\title{
Income Inequality and Household Labor ${ }^{*}$
}

\author{
Daniel Schneider
}

University of California, Berkeley

Department of Sociology

Orestes P. Hastings

Colorado State University

Department of Sociology

Published in Social Forces. Full Citation:

Schneider, Daniel and Orestes P. Hastings. 2017. "Income Inequality and Household Labor." Social Forces 96(2):481-506.

\footnotetext{
* Daniel Schneider (Corresponding author): UC Berkeley, Department of Sociology, 480 Barrows Hall, Berkeley, CA 94720; djschneider@berkeley.edu. The authors are grateful to Feinian Chen, Neil Fligstein, Ruth Milkman, Lynn Prince Cooke, and Judith Treas for helpful comments on earlier versions of this manuscript. The authors thank the Institute for Research on Labor and Employment (IRLE) at UC Berkeley for research support. A previous version of this paper was presented at the 2016 Meetings of the Population Association of America and the 2015 Annual Meetings of the American Sociological Association.
} 


\begin{abstract}
Income inequality has increased dramatically in the United States since the mid 1970s. This remarkable change in the distribution of household income has spurred a great deal of research on the social and economic consequences of exposure to high inequality. However, the empirical record on the effects of income inequality is mixed. In this paper, we suggest that previous research has generally overlooked a simple but important pathway through which inequality might manifest in daily life: inequality shapes the ability of women to outsource domestic labor by hiring others to perform it. One important venue where such dynamics might then manifest is in time spent on housework and in particular in the time divide in housework between women of high and low socioeconomic status. We combine micro-data from the 2003-2013 American Time Use Survey with arealevel data on income inequality to show the class divide in housework time between women with a college degree and from high earning households and women of lower socio-economic status is wider in more unequal places. We further assess whether this gap can be explained by domestic outsourcing by combining micro-data from the 2003-2013 Consumer Expenditure Survey with arealevel inequality and show that the gap in spending for household services between households of high and low socio-economic status also increases in contexts of higher inequality.
\end{abstract}




\section{INTRODUCTION}

Income inequality in the United States has risen sharply over the past forty years. The top 10\% of earners now command nearly $50 \%$ of total income and the Gini has risen to levels not seen since the Gilded age (Piketty and Saez, 2014). However, there is still disagreement about the effects of income inequality on social and economic life. At one extreme, scholars such as Wilkinson and Pickett (2009) argue that living in a high inequality regime has pronounced negative effects on both rich and poor on multiple dimensions of health and social well-being. At the other, scholars such as Deaton (2003) suggest that some of these inequality effects have a weak empirical basis.

But, prior research has largely overlooked a natural site for the manifestation of inequality effects: the more unequal the incomes of the rich and the poor, the better able the rich are to hire the poor to perform domestic labor, and the more difficult it may be for the middle class to do the same. That is, economic relations of household servitude are enabled by contexts of high inequality. Importantly, the ability to hire domestic laborers is contingent not on absolute income, but on income differentials. We argue that such relations of domestic service are both a natural implication of inequality and one of the clearest manifestations of inequality in everyday life, shaping power relations as people interact with one another and generating inequalities in the daily allocation of time.

This work also makes a contribution to sociological research primarily concerned with housework. There are large and persistent inequalities in housework time by gender and the literature on housework has then been quite reasonably focused on gender inequality. Some prior research has focused on the class inequalities inherent in paid domestic labor arrangements (Romero, 1992; Ehrenrich and Hochschild, 2002). However, relatively little work has examined class inequality in housework time in the United States. We build on this literature, turning attention to inequality in housework between women by class.

We examine the relationship between income inequality and the class divide in women's housework time within the United States. We merge state-level data on income inequality based on IRS tax data with time diary data from the American Time Use Survey (ATUS). Our analysis advances the small body of related empirical work by better accounting for sources of unobserved heterogeneity in the relationship between income inequality, class, and housework by measuring inequality at the subnational level, and by using high quality time diary data to measure housework time. We find that highly educated and high-income women do less housework than their less advantaged counterparts and we show that this class gradient in housework time is steeper in more unequal contexts. We then look directly at the hypothesized mechanism: domestic outsourcing through hiring housekeeping services, sending out laundry, and purchasing prepared foods. We draw on data from the Consumer Expenditures Survey (CEX) and show that, as expected based on theory and the time-diary results, the class-gradient in expenditures on domestic outsourcing is steeper in more unequal places. 


\section{INCOME INEQUALITY AND DOMESTIC SERVICE}

Income inequality does not simply capture the distribution of household incomes at a given point in time. It can also be thought of much more broadly, as setting the context within which we define what it means to be "rich" and what it is to be "poor." In their classic statement of this idea, Jencks et al. (1972) write that,

The rich are not rich because they eat filet mignon or own yachts... The rich are rich because they can afford to buy other people's time. They can bire other people to make their beds, tend their gardens, and drive their cars. These are not privileges that become more widely available as people become more affluent. If all workers' wages rise at the same rate, the highly paid professional will have to spend a constant percentage of his income to get a maid, a gardener, or a taxi.

Levels of income determine the amount and kinds of many sorts of goods that individuals can purchase. But, household services are quite different. The ability to hire a maid, gardener, or cook or to purchase meals prepared by others depends not on the level of one's income but on the gap between the income of the prospective employer and the wage of the employee. Inequality permits this kind of domestic economic arrangement and, in Jencks et al.'s (1972) telling, reveals the rich and the rest.

In an even earlier expression of this idea, George Stigler (1946) conjectured that more than simply the mean level of affluence in a society, the distribution of incomes could shape the demand for domestic service as, "a society with relatively many families at both ends of the income scale would provide both a large supply of servants and a large demand" (p. 6). In essence, and anticipating Jencks et al. (1972) by 25 years, Stigler (1946) argues that income inequality enables economic relations of domestic service. While domestic servants are certainly less common today than at any point in the last 100 hundred years, there has been an enormous expansion of workers in the service industry that provide replacements for home production (Kornrich, 2012).

Stigler's (1946) observation and Jencks et al.'s (1972) broad account of income inequality and paid domestic labor are persuasively elaborated by Sassen (1991), who notes that the rise of knowledgebased high-compensation industries increased inequality, but also reorganized lower-skill segments of the economy, shifting work to the service sector and personal care industries, including restaurants and domestic labor. Indeed, the causal arrow runs from economic restructuring to an increase in highest-earning workers to the demand for low-income workers providing substitutes for unpaid home production.

Both Parrenas (2015) and Hondagneu-Sotelo (2007) also describe how "reproductive labor," encompassing both childcare and housework, is purchased by affluent women from poorer women employment relations that are enabled by income inequality on a global scale. This phenomenon is not though confined to the global elite resident in Sassen's (1991) cities. Rather, the dynamics of inequality and household labor mean that a broad segment of affluent American women are relieved of their household work (Parrenas, 2015). 
Finally, Milkman and colleagues (1998) draw these strands of research together and contrast the prediction that rising income inequality would increase the use of paid domestic labor with the predictions of modernization theory, which suggested a waning and ultimate end to domestic service with increasing economic development (e.g., Coser, 1973). Milkman et al. (1998) come down squarely on the side of Jencks et al. (1972) and Sassen (1991), succinctly stating, "it is logical to expect that the greater the extent of economic inequality in a community-in other words, the greater the disparity in resources between rich and poor households-the more easily rich households can afford to employ less fortunate persons as domestic servants" (p. 496). Milkman et al. (1998) then provide a brief empirical illustration of this idea, taking a sample of US cities and showing a positive correlation in cross-sectional 1990 Census data between household income inequality and the share of female workers employed in private households in domestic service.

These treatments of inequality, affluence, and paid labor are purposefully broad. But, this theoretical architecture also suggests several more specific implications. First, we would expect that households with more economic resources will be more likely than those with fewer resources to outsource household labor by hiring the "people to make their beds, tend their gardens, and drive their cars," and we would add prepare their meals, whom Jencks et al. (1972) allude to. Second, we would expect these behaviors would widen class divides among women in time spent on those activities-the routine housework of everyday life. Finally, and most importantly, the ability of affluent households to outsource their household labor should be most pronounced in contexts of high inequality and the ability of less affluent women to purchase meals out or hire a household cleaner should be constrained in contexts of high income inequality. Consequently, class divides in women's housework time should be most evident when and where inequality is high.

\section{PRIOR EMPIRICAL RESEARCH}

Despite the recurrent reference to household labor relations in accounts of inequality and the centrality of this idea to ethnographies of domestic labor, there has been little empirical work that directly investigates these dynamics at scale. The question of whether inequality shapes the class gradient in women's housework time through the differential use of paid household labor has been touched on, however, by several related strands of quantitative research.

\section{Social Class and Outsourcing Household Labor}

Sociologists have long recognized the use of domestic outsourcing by affluent households. Veblen (1899) offers an early account of such behavior and more contemporary accounts frame this behavior in terms of a market logic, with Bianchi et al. (2000) writing, "a higher absolute level of education may limit housework because it increases a person's.... ability to outsource tasks."

Much of the contemporary empirical research on outsourcing in the United States makes use of the CEX, since, as Heisig (2011) notes, direct questions on the use of paid household labor are rare in representative surveys. This work documents a strong positive relationship between expenditures on household outsourcing, generally defined to include housekeeping services, laundry, and prepared 
meals, and household income (Treas and de Ruitjer, 2008; de Ruijter, Treas, and Cohen, 2005; Spitze, 1999). Women with at least a college education are also more likely to make expenditures on household outsourcing than their less educated counterparts (Treas and de Rutijer, 2008; de Ruijter, Treas, and Cohen, 2005). In all, the prior empirical scholarship on outsourcing and class shows the expected relationship between affluence and domestic outsourcing, with more educated women and higher income households more likely to report outsourcing expenditures.

\section{Class Gradients in Women's Housework Time}

While the literature on housework is quite focused on gender differences in housework time, recent research has found that there are meaningful divides between women of high and low socioeconomic status (SES) in the amount of time spent on housework.

For instance, analyzing data from the ATUS, England and Srivastava (2013) find that, among couples in which both spouses are employed, women with less than a high-school education spend $30 \%$ more time on housework per day than women with a college degree or more. Cooke and Sayer (2012) find evidence of a similar gap in their analysis of the Multinational Time Use Data from 2003, showing evidence of this class divide among all women and among mothers. Killewald (2011) uses data from the Health and Retirement study to show that college educated women do significantly less cleaning and cooking than their less educated counterparts.

While these results follow a recent move towards specific consideration of the class-divide in housework time, we note that these findings mirror earlier results that also found that women's housework time declined with education (reviewed by Shelton and John, 1996) and with household income (Brines, 1993; South and Spitze, 1994; Schneider, 2011).

\section{Income Inequality and Class Divides in Women's Housework}

Finally, three recent papers connect class divides in women's housework time and the role of outsourcing with exposure to income inequality. In the most comprehensive examination to date, Heisig (2011) marshals data from the 2002 International Social Survey Programme to examine the correlates of differences in housework time between women in the top decile of households by income and women with lower household incomes. He finds that the class-gradient in women's housework time is steeper in countries with higher inequality, as measured by the country-level Gini coefficient, controlling for individual, household, and country characteristics. Heisig (2011) then suggests that domestic outsourcing is the underlying mechanism by which income inequality affects class gradients in housework time.

Gupta et al. (2010) similarly compare high and low-income women's housework time across countries and also find evidence of a class gradient in housework time, with affluent women spending less time on routine chores than their poor counterparts. Their analysis is limited to only three countries - the United States, Germany, and Sweden-and so does not permit a detailed quantitative examination of the effect of country-level inequality on this gradient. But, they note that this class divide is largest in the United States, where income is also most unequally distributed, and is substantially smaller in both Sweden and Germany, where inequality is lower. Cooke and Sayer 
(2012) undertake a very similar empirical analysis, but compare the United States, Australia, and the United Kingdom. While all three are relatively high-inequality countries, the authors find that class divides in women's housework are least pronounced in relatively low-inequality Australia and highest in the United States. In each of these three studies, it is not so much the cross-national comparison of the levels of affluent and poor women's housework time that matters, but rather the comparison of the gaps between those of high and low-SES.

\section{Limitations of Existing Research}

These recent analyses adopt innovative strategies to examine how aggregate inequality affects household labor. This contribution is quite notable, since, as Treas and Liu observe (2013), "classbased housework inequality has been overshadowed by gender-based disparities, but societal income inequality is important." However, these analyses are limited in some crucial respects.

First, while the cross-national design employed by Heisig (2011), Gupta et al. (2010), and Cooke and Sayer (2012) is common in the literature on inequality effects, this design risks confounding the effects of inequality with other unobserved characteristics of countries that shape both inequality and housework patterns. This kind of omitted variables bias is a particular problem here because all three studies employ cross-sectional data rather than use the kind of panel data that might allow for estimates that exploit temporal variation in inequality within-country and so can net out timeinvariant country-level characteristics. These problems bedevil many attempts to estimate the effects of inequality on social and economic life.

Second, while theory often posits that individual-level outcomes will be shaped by area-level inequality, this same theory is often quite vague as to the appropriate unit of aggregation at which inequality should be measured. For instance, in the literature on inequality and health, where social comparison is an important mechanism, there is no strong theoretical argument regarding whether inequality should be considered at the country-level, the state-level, the city-level, or even at the level of the social network or workplace (Wilkinson and Pickett, 2009). But, there is much less ambiguity regarding the appropriate unit of aggregation in the case of household labor. Since the hypothesized mechanism involves hiring other people to do housework and prepare meals, then it stands to reason that inequality should be measured at a unit of aggregation that plausibly captures the local labor market. The country is probably too big, the census tract much too small. For the United States, we would expect that an intermediary level of aggregation, such as the Metropolitan Statistical Area, the Commuting Zone, or the state would be appropriate.

A third issue with the existing work on inequality and household labor is commonly noted in the literature on housework. Both Heisig (2011) and Gupta et al. (2010) use either a single catch-all question about housework time or the sum of several such questions about specific housework activities. While the use of such measures is common in the housework literature, time diaries, in which respondents provide a detailed accounting of their daily activities in small increments of time, are known to be much more reliable (Kan, 2008). 
Finally, fourth, though the studies described above rely on the idea that inequality increases the class gradient in housework time by allowing affluent households to outsource household production, Heisig (2011), Gupta et al. (2010), and Cooke and Sayer (2012) do not actually show that such outsourcing occurs. And, some skepticism about the ability of women to actually use outsourcing to reduce housework time may be warranted. For instance, drawing on a sample of older dual earner couples, Killewald (2011) shows that outsourcing accounts for surprisingly little of the negative relationship between women's own income and housework time. Recent analysis of Australian data however finds the opposite, that outsourcing does help women to reduce their housework time (Craig et al., 2016).

Other possible mechanisms connecting income inequality with housework time seem less likely, but they are possible. For instance, men married to affluent women in high inequality contexts might do more housework or affluent women in such contexts might have different standards for cleanliness. In short, the preferred mechanism of outsourcing is difficult to accept without some supporting evidence.

\section{Contributions}

We advance the very small body of empirical research on income inequality and household labor both by grounding our investigation in theory on the effects of inequality and by conducting a more rigorous empirical investigation of these relationships. We do so by first merging individual-level time diary data from the ATUS with state-level measures of income inequality calculated based on IRS tax data. We examine how the class gradient in women's housework time varies with the level of income inequality in the state of residence. Second, we perform a similar analysis of data from the CEX, again merging individual level data on domestic outsourcing expenditures by class with arealevel data on income inequality. This analysis allows us to directly examine the proposed mechanism connecting income inequality with class differences in women's housework time. We show that that the class gradient in domestic outsourcing similarly varies with area-level income inequality.

This approach advances prior research in four key respects. First, the ATUS is a repeated crosssectional survey that has been conducted each year since 2003. Our models minimize omitted variables bias by including state and year fixed effects as well as a set of individual, household, and time-varying state-level controls. Second, this design allows us to use a finer-level of geography than the nation when measuring inequality. Here, we focus on how state-level inequality affects the class gradient in housework time. Third, the ATUS offers high quality time diary data rather than stylized catch-all questions about housework time. This data increases confidence in the accuracy of our estimates. Finally, fourth, we draw on data from the CEX to investigate the proposed mechanism behind the inequality-class gradient in housework relationship, examining if the class-gradient in the outsourcing of household work also varies with state-level inequality. 


\section{DATA AND METHODS}

We begin below by describing the ATUS and the data on area-level income inequality, the key data sources for our analysis. We then introduce our analytical methods and detail a number of robustness checks that we apply to these main models. Finally, we introduce the CEX and describe how we use this data to test domestic outsourcing as the causal pathway relating area-level income inequality and the class gradient in women's housework time.

In both datasets, we focus our main analyses on married women with children. We follow prior research on housework and outsourcing in the United States and restrict our primary analysis to married women between the ages of 18-64. We also impose the additional criterion that these women live with at least one child under age 18 as we expect that women managing the multiple duties of partner, mother, and worker will be most likely to seek to outsource household labor, if possible. This logic follows Milkman et al.'s (1998) point that demand for household domestic services is likely to be highest in families with children due to the difficulty women face of managing employment, housework, and childcare in the face of persistent inegalitarian divisions of household responsibility. We exclude cohabiting couples because such couples are much less likely to pool incomes than married couples (i.e., Heimdal and Houseknecht, 2003) although the results are robust to including cohabiters.

More practically, limiting the sample to married mothers helps us to solve a set of otherwise serious empirical problems. First, by focusing on couples, we ensure that we are examining the primary couple within a household and do not mistake high household income that is controlled by others in the household (for example, adult parents of the respondent or roommates) for resources available to the female respondent. Second, focusing on couples allows us to investigate the potentially very important dynamics around women's and men's own earnings and housework time as distinct from household income and housework time. Third, beyond the respondent, we only have detailed information on the spouses of respondents and lack the same degree of detail for other adults in the household. In non-couple households, the failure to adjust for those characteristics may be particularly important. Finally, fourth, the formal and informal contributions of non-resident partners (Edin and Lein, 1997) are unlikely to be captured in our data and their omission is likely to bias any results that rely on comparison between married and unmarried women.

\section{American Time Use Survey}

Our key source of individual-level data is the ATUS, which provides annual nationally representative estimates of Americans' time use using a detailed time diary methodology. The ATUS selects a sample of the respondents each year from the Current Population Survey (CPS) and has each respondent use detailed time diaries to track their time use for a full day. Respondents are asked to report retrospectively on what activities they were engaged with in fifteen-minute periods throughout the diary day, beginning at 4:00AM and continuing over the next 24 hours. We use ATUS data from 2003 (the first year of the survey) through 2013 (the final year that we have the state-level inequality data described below). 


\section{Housework Time}

Our dependent variable is the amount of time in minutes per day that respondents spend conducting housework. We define housework as including time spent (1) cleaning the residence and storing goods (coded 020101 and 020104), (2) doing laundry, sewing, or ironing (coded 020102 and 020103), (3) food and drink preparation, service, and clean-up (coded 020202, 020203, and 020201), (4) grocery shopping (coded 070101), and (5) travel associated with each of these activities. We remove respondents reporting housework time above the 99th percentile to avoid unduly influential observations. Our measure does not include any housework done for pay, and so any changes in low-SES women's housework time should not be the product of an increase in time spent by lowSES in paid domestic labor for others. We also test a disaggregated measure in which we separate time spent on food preparation, service, clean-up, and grocery shopping from the other core housework tasks.

\section{Socio-Economic Status}

We are interested in the difference in the amount of time spent doing housework between high-SES women and other women, and how that difference varies with state-level inequality. The great majority of the literature on housework has focused on gender, rather than class, divides in housework time. However, the small literature on class and housework provides some guidance for how SES can be usefully operationalized. We follow this literature and construct two measures that determine which women are high-SES: (1) whether or not a woman has completed at least a Bachelors degree and (2) whether or not a woman's family has a high income. ATUS income was collected in income bins, and we define high income as being in one of the two highest bins, which requires an annual family income of at least $\$ 100,000$. We also found similar results using only the top income bin (annual income of $\$ 150,000+$ ). The choice of these measures is guided by the focus in the prior literature on class divides in housework time and outsourcing by college completion (e.g., Treas and deRutijer, 2008; de Ruijter, Treas, and Cohen, 2005) and by household income (e.g., Brines, 1993; South and Spitze, 1994). When discussing these measures we refer to high-income and highly-educated women using the terminology of class, affluence, and socio-economic status.

\section{Individual-Level Controls}

We use a number of additional individual-level independent variables about the respondent in order to control for characteristics that might bias the relationship between high-SES, inequality, and housework. We include controls for both respondent and spouse's age, age squared, and race/ethnicity (non-Hispanic-White, non-Hispanic-Black, non-Hispanic Native American/Pacific Islander, non-Hispanic Asian, non-Hispanic multi-race, Hispanic); spouse's education; household size; homeownership; and whether a household was located in an MSA.

For respondents, we also control for if the respondent is unemployed, out of the labor force, or absent from work (all in the preceding week), and usual weekly work hours (but excluding respondents reporting variable work hours). For spouses, we control for if the spouse is unemployed in prior week, absent from work in prior week, and weekly work hours. The inclusion of these 
measures is especially important since increased work effort could both raise household socioeconomic status and reduce housework time (as well as contribute to aggregate income inequality). Finally, we include three indicator variables for if the diary day was Saturday, Sunday, or a holiday.

\section{Area Level Measures of Income Inequality}

Our area-level measures are drawn from several sources. The measures of inequality are constructed by Frank and colleagues from income tax data published in the IRS's Statistics of Income. Our analyses focus on both the Gini coefficient and the top 10\% income share, which are constructed at the state-year level (Frank et al., 2015; Frank, 2014). The Gini is defined as the average distance between all pairs of proportional income in the population and can thus range from 0 (if everyone had the same income) to 1 (if one person had all the income). The Gini assesses inequality across the entire income distribution and is the most commonly used measure of inequality. However, we also use the top $10 \%$ income share, as our interest is in the extent to which high-SES women can purchase the labor of others and the extent to which high inequality may inhibit outsourcing by less affluent women. These two measures effectively summarize the distributions of income relevant to this question.

While our choice of analysis years is primarily guided by the availability of the high-quality time-diary data offered by the ATUS, the years 2003-2013 are also characterized by high and increasing income inequality. Figure 1 presents box plots of our two preferred measures of state-level inequality, showing the between-state and over-time variation in these measures of inequality for our analysis period (figures with the mean and range of inequality for every state are also available in Online Appendix 1). Consistent with national-level accounts (e.g., Piketty and Saez, 2014), these data show rising inequality until the Great Recession, a sharp fall, and then a rebound. This non-linear variation in inequality over the analysis years complements the moderate cross-state variation in inequality levels.

\section{Figure 1. Box Plot of State-Level Income Inequality by Year}



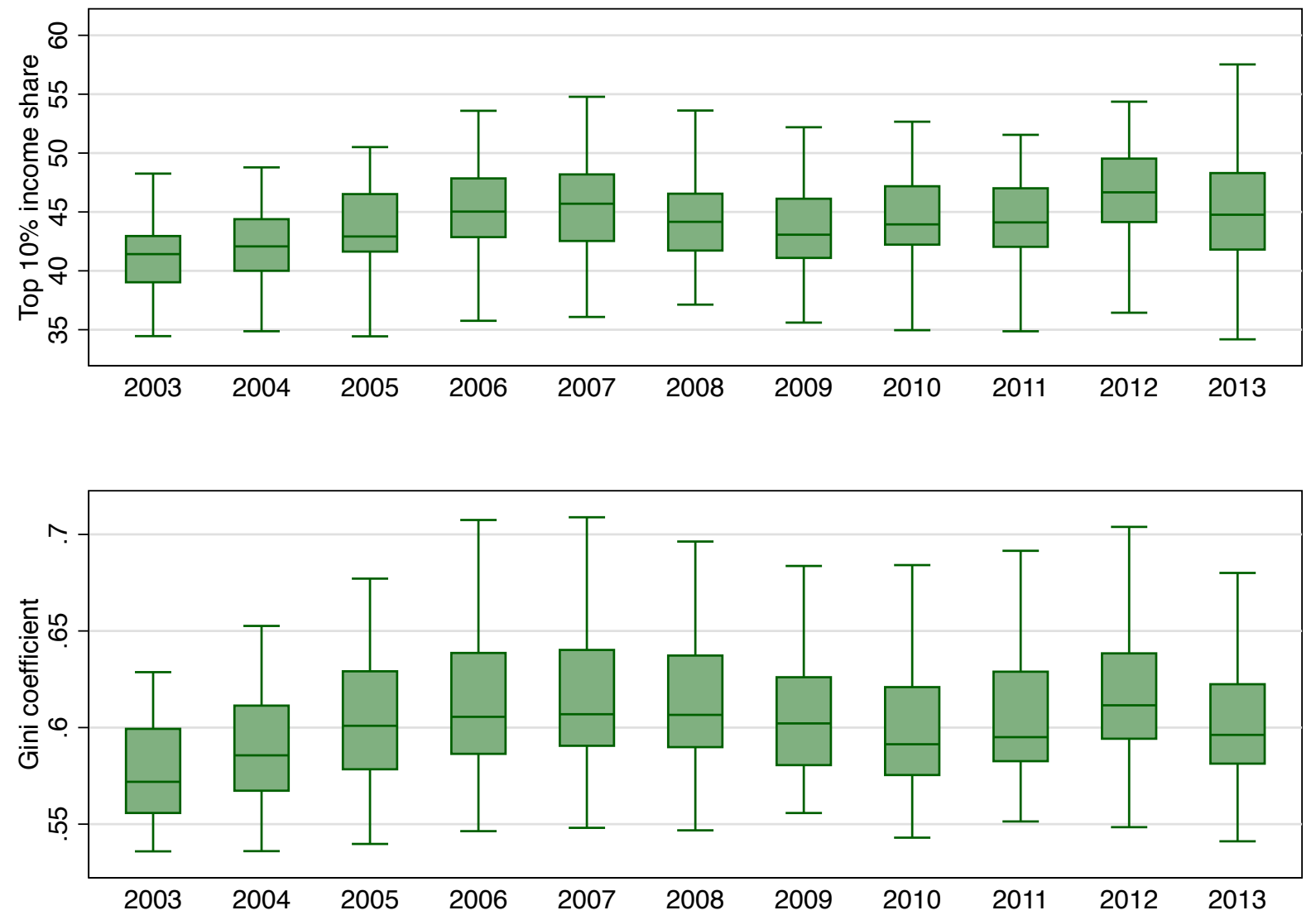

\section{Area-Level Controls}

We also include a number of additional state-level independent variables in our models: the annual unemployment rate, mean income, proportion married, proportions by race/ethnicity (non-Hispanic white, non-Hispanic black, and non-Hispanic others [i.e., not white or black-predominantly Asian], which leaves Hispanic as the baseline), and the proportion of working age (16-65) immigrant women with no more than a high-school education and not in school among all not-in-school working-age women. The last measure may capture some variation in the size of the amount of available labor in so far as low-income female immigrants are more likely to do paid housework for others, and thus may affect the extent to which affluent women pay other to do housework for them through a separate pathway from income inequality. ${ }^{1}$ The state-level unemployment rate is from the BLS. The remaining measures were calculated using the ACS public-use microdata made available in IPUMS. Using the state of residence and interview year in the ATUS data, we match respondents with their corresponding area-level measures. Descriptive statistics for all of our individual- and area-level variables are in Online Appendix 2. 


\section{Analytical Methods}

\section{Main Analytic Models}

We estimate a linear regression model of the amount of daily time spent on housework based on a number of individual- and state-level covariates. Formally, consider person $i$ living in state $s$ surveyed in year $t$. The individual-level regression equation we estimate is

$$
H W_{i s t}=\beta_{0}+\beta_{1} I N E Q_{s t}+\beta_{2} S E S_{i s t}+\beta_{3} I N E Q_{s t} \times S E S_{i s t}+\boldsymbol{\beta}_{\mathbf{4}}^{\prime} \boldsymbol{Z}+\gamma_{s}+\theta_{t}+\epsilon_{i s t}
$$

$H W_{i s t}$ is minutes of housework per day, $I N E Q_{s t}$ is either the Gini or top $10 \%$ income share, and $S E S_{i s t}$ is either having a college degree or household income of greater than $\$ 100,000$. We also find substantively identical results using a one-year lagged inequality measure (i.e., $\left.I N E Q_{s, t-1}\right) . \boldsymbol{Z}$ is a vector of individual and state-level controls, $\gamma_{s}$ and $\theta_{t}$ specify full sets of indicators for the state and the year (i.e., two-way fixed effects), and $\epsilon_{i s t}$ is the idiosyncratic error. The two-way fixed-effects model provide us with a relatively strong form of causal inference because it accounts for any constant features of each state over the time period being analyzed (through the state fixed effects) as well as any national level year-to-year changes (through the year fixed effects). We employ the sampling weights provided by the ATUS and adjust the standard errors for clustering within states.

Given our interest in how the class-gradient in women's housework times varies with state-level inequality, our focus is on $\beta_{3}$, the coefficient of the interaction term between inequality and our high-SES indicator. A negative $\beta_{3}$ would support the idea the hypothesis of widening class-divides with income inequality.

We estimate four versions of our main model, varying our measures of SES (completed college or high family income) and of inequality (Gini or top 10\% income share). We report the main effects of class and inequality and their interaction (that is, $\beta_{1}, \beta_{2}$, and $\beta_{3}$ ) in the main text and then graph the predicted values for each SES class across the inequality distribution (as measured by the Gini and top $10 \%$ share) in order to illustrate how the class gradient on housework time varies by the level of inequality. In Online Appendix 3 we present all the coefficients from the main model. We use the same controls in all of our models, except that in models where completing college is our high-SES indicator, we also control for family income, and in the models where high family income is our high-SES indicator, we control for completing college.

As noted above, we restrict our primary analysis to married women between the ages of 18-64 with at least one child under age 18 . We exclude 325 cases where the women reported a working age (less than 65 years of age) parent or relative in the home that was older than the respondent in order to avoid misattributing that persons' resources to the respondent (though we find nearly identical results when including them). 
Applying the sample inclusion criteria described above yields a sub-sample of 20,617 ATUS respondents with non-missing housework time data. We omit cases with missing data on any of the individual-level covariates (most of missing data comes from refusal or non-response on family income), leaving 18,966 cases for the main analyses. We checked there were no meaningful differences (substantively or statistically) between the dropped cases and the complete cases in the final model in terms of the amount housework time reported or the level of state-level inequality experienced.

We also supplement the main results with six additional tests detailed in Online Appendix 4. First, we examine how the results respond to substituting several different measures of state-level inequality in place of our two preferred measures. Second, we examine the sensitivity of the results to substituting Combined Statistical Area (CSA) level inequality in place of state-level inequality (but we can only do this for a small subsample of respondents because of data limitations). Third, we examine the sensitivity of our results to the exclusion of our preferred set of controls. Fourth, we assess the potential effects of outlier states. Fifth, we test the relationship between women's own income and class-gaps in housework time given prior research that shows an important role for women's own income in shaping housework time (Gupta, 2006). Finally, we re-estimate our main models, taking men's housework time as the outcome variable.

\section{Mechanisms}

Our main models examine how the class gradient in women's housework time varies by area-level income inequality. While theory suggests that inequality should increase class-gaps in women's housework time by influencing the outsourcing of domestic labor, other pathways are possible and are not excluded by this analysis of the class gradient in women's housework time. There is very little data generally available on who hires domestic workers. So, we marshal data from the CEX to examine expenditures on domestic outsourcing. The expenditure data allow us to assess whether there is a similar class divide in expenditures on domestic outsourcing, as we hypothesize for time in domestic labor.

However, these data do not allow us to examine exactly what this money buys in terms of, for example, the number of meals eaten out or the number of hours of cleaning services. That is, we do not observe what we might call the "price per unit" of domestic services or the number of such "units" purchased. We only observe the total amount spent on domestic outsourcing. Because the price of a "unit" of domestic services is likely to be lower in high inequality contexts and the ability of high-income households to purchase "units" is also likely to be greater in high inequality contexts, it is not clear what the relationship between inequality and total household expenditures on domestic outsourcing will be for affluent women.

Because we do not have a strong prior on how high-SES women's total domestic expenditures will vary with inequality, we again focus on the difference between high- and lower-SES women, here in expenditures on domestic outsourcing. For a given state-year, the "price per unit" of domestic services will be the same for both groups, and so any widening disparities in outsourcing with inequality will reflect differences in outsourcing by class along the extensive margin. 


\section{Consumer Expenditures Survey}

We draw on detailed data on household expenditures on domestic outsourcing from the CEX, which collects information on the expenditures, income, and characteristics of a nationally representative sample of households in the U.S. Although the program consists of two components-an Interview survey and Diary survey-only the Interview survey measures housework expenditures, which are collected quarterly for each household for 12 consecutive months. We analyze CEX micro data from 2003-2013 (all expenditures and income are adjusted to 2013 real dollars using the CPI-U-RS series). We organize the data into a household-quarter structure (a household could be present between 1 and 4 times in the final dataset). Quarters can begin in any month and the start-month for a quarter is simply determined by the first month of interview. Consequently, quarters can span more than one calendar year. In such cases, we assigned the quarter to the year during which most of the quarter occurred (e.g., a quarter of Nov 2011/Dec 2011/Jan 2012 would be assigned to 2011, but a quarter of Dec 2011/Jan 2012/Feb 2012 would be assigned to 2012). Based on the state where the consumer unit lived and the year of the quarter, we matched each observation to the corresponding area-level measures, including state-level income inequality. ${ }^{2}$

\section{Measures of Domestic Outsourcing.}

Our dependent variable is expenditures on housework. We consider three possible types of expenditures that correspond to the domestic outsourcing of the tasks measured in the time-use analysis above: (1) "Housekeeping services", (2) "Services at the dry cleaners and laundry for clothing items" (not including self-service laundry machines), and (3) "Expenditure for dinners, other meals, or snacks in restaurants, cafeterias, cafes, drive-ins, or other such places." These measures do not include gardening and lawn care services, or babysitting and nanny services, replacements for activities that we do not consider housekeeping and activities that are not included in our time-use estimates from the ATUS. To avoid unduly influential outliers, we drop the top 1\% of expenditures in each category (though we find substantively identical results when including them). We also considered models that disaggregate expenditures on housekeeping services from those on prepared meals, and discuss these alternative models in our results as well.

\section{Measures of SES}

We use two measures of high SES: women's college completion and high household income, measured after the fourth quarter in reference to the previous 12 months. As we did for the ATUS, we designate "high family income" as an annual pre-tax income of $\$ 100,000$ or more. We also control for household size, husband and wife's age, age squared, race/ethnicity, residence in an MSA, work hours, and a dichotomous measure of any work hours. At the state-level, we use the same set of controls as in the main model of housework time. 


\section{Analysis of the Domestic Outsourcing Mechanism}

We estimate a linear regression model of quarterly expenditures dedicated to replacing housework. We focus on the coefficient of the interaction term between inequality and our high-SES indicator. As inequality increases, we expect the gap in expenditures between high-SES women and other women to widen. A positive coefficient would support this. But, as discussed above, we do not have a strong prior on the slope of the relationship between inequality and outsourcing expenditures for high-SES women.

We use the same sample restrictions as in our main models: married households with children where a women between the ages of 18-64 is reported as either the household head or a the wife of the household head, excluding cases where there was a working age (less than 65 years of age) parent or relative in the home that was older than the woman (though our results are robust to including them). All models include household- and state-level covariates as well as state and year fixed effects. We employ the sampling weights provided by the CEX and adjust the standard errors for clustering within states. ${ }^{3}$

\section{RESULTS}

We begin our analysis with a simple graphical illustration. For our entire sample, we calculate the average amount of housework time for women in each SES subgroup and in Figure 2 plot the average difference between women with and without a college degree and with and without a high family income against the average top 10\% income share and Gini for each state. We find modest support for the proposed relationship: in states where inequality is higher, women of high SES spend even less time than other women doing housework.

These simple bivariate results suggest that the class gradient in women's housework time varies with the level of income inequality in the state of residence. We explore this relationship further in our main models that can control for a number of potential individual- and state-level confounders. 
Figure 2. Class Differences in Minutes of Housework per Day by State Income Inequality Levels (State averages, 2003-2013)

\section{With vs without bachelors degree}
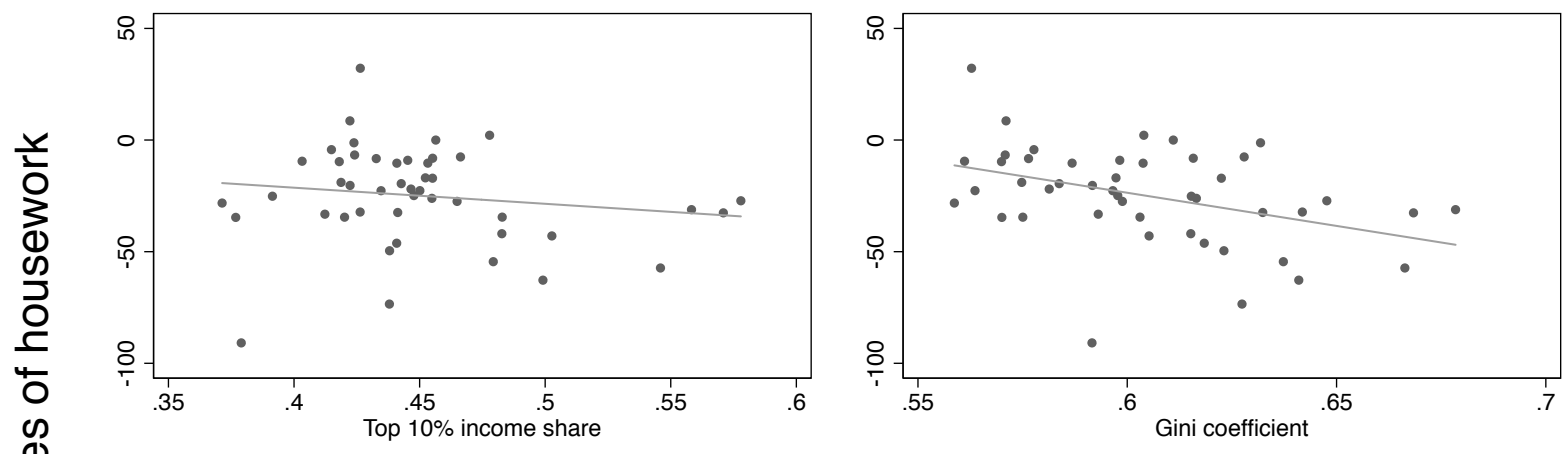

With vs without high family income
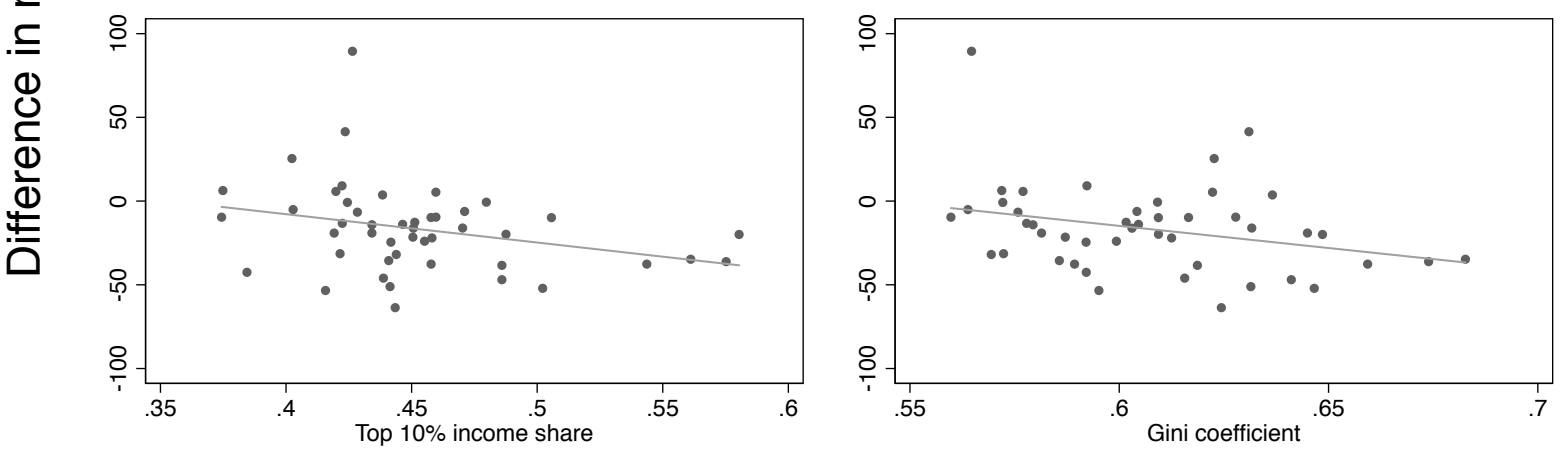

\section{Inequality and The Class-Gradient in Women's Housework}

Table 1 presents the key results of our analysis (the full set of regression coefficients for all covariates are presented in Online Appendix 3). The inequality coefficients represent the extent to which the amount of housework time would be predicted to change for non-high-SES women as inequality varies, the high-SES coefficients represent the expected difference by SES in housework time at the mean-level of inequality, and the interaction term shows how we much less we would expect high-SES women would work given the same level of inequality. These results are based on within-state changes net of the national change in a given year and net of the individual-level and time-varying state-level controls. 
Table 1. Effects of Income Inequality on Class-Gaps in Women's Housework Time

\begin{tabular}{|c|c|c|c|c|}
\hline & Model 1 & Model 2 & Model 3 & Model 4 \\
\hline \multicolumn{5}{|l|}{ Interaction of Inequality and SES } \\
\hline Completed college $\times$ Top $10 \%$ income share & $-67.2^{*}$ & & & \\
\hline High Family Income $\times$ Top $10 \%$ income share & & $-78.2^{* *}$ & & \\
\hline Completed college $\times$ Gini coefficient & & & $-123.3^{* *}$ & \\
\hline High Family Income $\times$ Gini coefficient & & & & $-119.7^{*}$ \\
\hline \multicolumn{5}{|l|}{ Inequality (mean centered) } \\
\hline Top $10 \%$ income share & 49.0 & 42.3 & & \\
\hline Gini coefficient & & & 83.5 & 74.2 \\
\hline \multicolumn{5}{|l|}{ Criteria for High-SES } \\
\hline Completed College & $-9.35^{* * *}$ & $-10.2^{* * *}$ & $-9.42^{* * *}$ & $-10.2^{* * *}$ \\
\hline High Family Income (dichotomous) & & $-6.07^{* *}$ & & $-6.14^{* *}$ \\
\hline Family income (continuous categories) & $-1.89^{* * *}$ & & $-1.88^{* * *}$ & \\
\hline Observations & 18966 & 18966 & 18966 & 18966 \\
\hline \multicolumn{5}{|c|}{$\begin{array}{l}{ }^{*} p<.05,{ }^{* *} p<.01,{ }^{* * *} p<.001 \\
\text { Note: Each model also includes individual-level controls, state-level controls, and state and year fixed } \\
\text { effects. The models are weighted and the standard errors are adjusted for clustering within states. The } \\
\text { set of coefficients are presented in Appendix } 2 \text {. }\end{array}$} \\
\hline \multicolumn{5}{|c|}{$\begin{array}{l}\text { In all four main models, the interaction term between inequality and SES is negative-ranging from - } \\
67.2 \text { to - } 123.3 \text {-and significant. }{ }^{4} \text { We illustrate the diverging differences in housework time in Figure } 3 \\
\text { by graphing the predicted difference in daily minutes of housework time between the SES groups } \\
\text { across the inequality distribution (10th to } 90 \text { th percentiles) while holding the remaining model } \\
\text { covariates at their mean values. The range of the each plot on the x-axis is the minimum and } \\
\text { maximum for that inequality measure observed in the data. Our model suggests that in periods and } \\
\text { places of low inequality there is little difference between the housework time of affluent women and } \\
\text { other women (note that by definition, lower income inequality means there is less difference in the } \\
\text { incomes of SES groups as well). As inequality increases, we find a sizable decrease in the housework } \\
\text { of high-SES women relative to other women. Notably, this widening gap is produced both by } \\
\text { decreases in the housework time of high-SES women and increases in the housework time of low- } \\
\text { SES women. }\end{array}$} \\
\hline
\end{tabular}


Figure 3. Class Differences in Predicted Minutes of Housework per Day by Income Inequality Levels

\section{housework(with BA) - housework(without BA)}
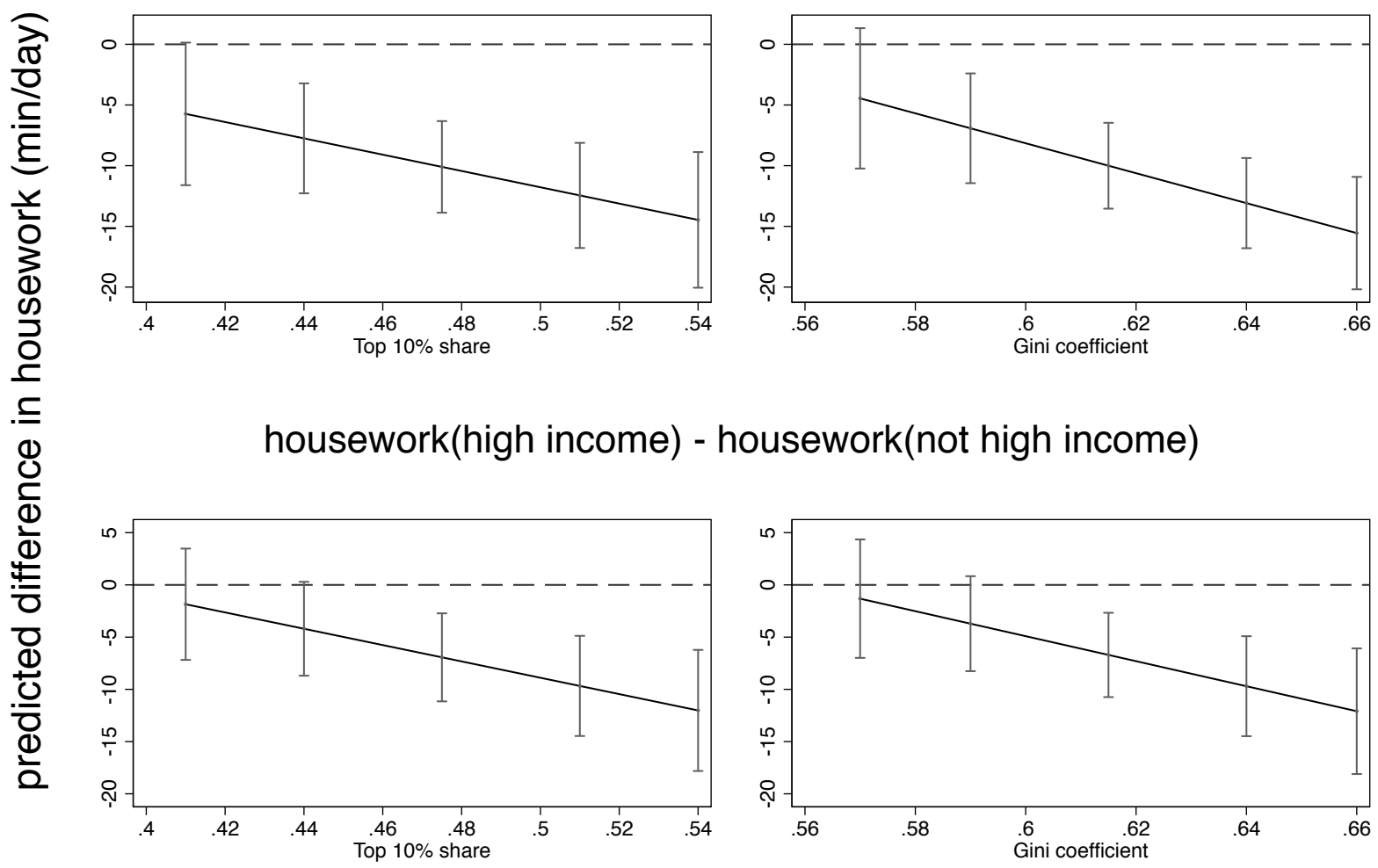

For example, in the top right plot of Figure 3, when the Gini index is .6 (the overall mean in our data), we expect that—all else being equal—college educated women would do an average of 8 fewer minutes of housework per day than non-college educated women. If the Gini were to increase to .65, we would expect college-educated women to do 14 fewer minutes of housework per day than non-college educated women. In the context of women's average daily housework time, this is not a large effect. However, while this increase may not seem large at the daily level, it translates into noncollege educated women spending an additional 36.5 hours per year doing forms of housework. Another way to "size" these effects is to compare their magnitude to the effect size of other more commonly studied variables. For instance, the full regression results reported in Online Appendix 3 show that an additional hour of women's market work time reduces her housework time by approximately 1.3 minutes. Our estimate of a 6 minute larger class gap in daily housework time due to a .05 increase in the Gini index is approximately equivalent to the housework time reduction realized when women work an additional 5 hours per week. 
Our findings are consistent with the expectation that the class-gradient in housework time varies by the level of inequality, and that the high SES women will spend even less time doing housework than other women as income inequality increases.

\section{Inequality and The Class Gradient in Domestic Outsourcing}

We next turn to our analysis of the CEX that is designed to assess if outsourcing is indeed a possible causal pathway by which contexts of inequality serve to increase class-differences in women's housework time. Table 2 shows the results of our analysis of household expenditures on outsourcing, focusing on the interaction between our measures of SES (women's college education and high household income) and state-level income inequality. Again, these results are based on within-state changes net of the national change in a given year and net of the individual-level and time-varying state-level controls.

Table 2. Effects of Income Inequality on Class-Gaps in Domestic Outsourcing Expenditures

\begin{tabular}{|c|c|c|c|c|}
\hline & Model 1 & Model 2 & Model 3 & Model 4 \\
\hline \multicolumn{5}{|l|}{ Interaction of Inequality and SES } \\
\hline Completed college $\times$ Top $10 \%$ income share & $700.9^{* *}$ & & & \\
\hline High Family Income $\times$ Top $10 \%$ income share & & $894.9^{* *}$ & & \\
\hline Completed college $\times$ Gini coefficient & & & $1199.3^{* * *}$ & \\
\hline High Family Income $\times$ Gini coefficient & & & & $1423.5^{* * *}$ \\
\hline \multicolumn{5}{|l|}{ Inequality (mean centered) } \\
\hline Top $10 \%$ income share & -524.4 & -490.9 & & \\
\hline Gini coefficient & & & 276.6 & 321.8 \\
\hline \multicolumn{5}{|l|}{ Criteria for High-SES } \\
\hline Completed College & $114.7^{* * *}$ & $76.69^{* * *}$ & $114.3^{* * *}$ & $76.22^{* * *}$ \\
\hline High Family Income (dichotomous) & & $321.2^{* * *}$ & & $322.1^{* * *}$ \\
\hline Family income (continuous categories) & $43.22^{* * *}$ & & $43.18^{* * *}$ & \\
\hline Observations & 63503 & 63503 & 63503 & 63503 \\
\hline
\end{tabular}

${ }^{*} p<.05,{ }^{* *} p<.01,{ }^{* * *} p<.001$

Note: Each model also includes individual-level controls, state-level controls, and state and year fixed effects. The models are weighted and the standard errors are adjusted for clustering within states.

In all four of the models, the coefficient is positive-ranging from 701 to 1424 -and statistically significant. We visualize these effects in Figure 4 by graphing the predicted difference in quarterly 
expenditures by SES group across the inequality distribution while holding the remaining model covariates at their mean values. Using the same comparison above, when the Gini index is .6, we expect that—all else being equal—households with college educated women would spend $\$ 98$ more per quarter on household outsourcing than other households. If the Gini were to increase to .65, that difference would increase to $\$ 158$ per quarter. Here too, we note that the wider class-divides in expenditures on outsourcing that we observe in higher inequality contexts are the product of both high-SES women spending more on outsourcing and, to some extent, low-SES women spending less, which accords with the idea that income inequality shapes the relative price of outsourcing to income differently by place in the income distribution.

\section{Figure 4. Class Differences in Predicted Dollars of Outsourcing Expenditures per Quarter by Income Inequality Levels}

\section{outsourcing(with BA) - outsourcing(without BA)}
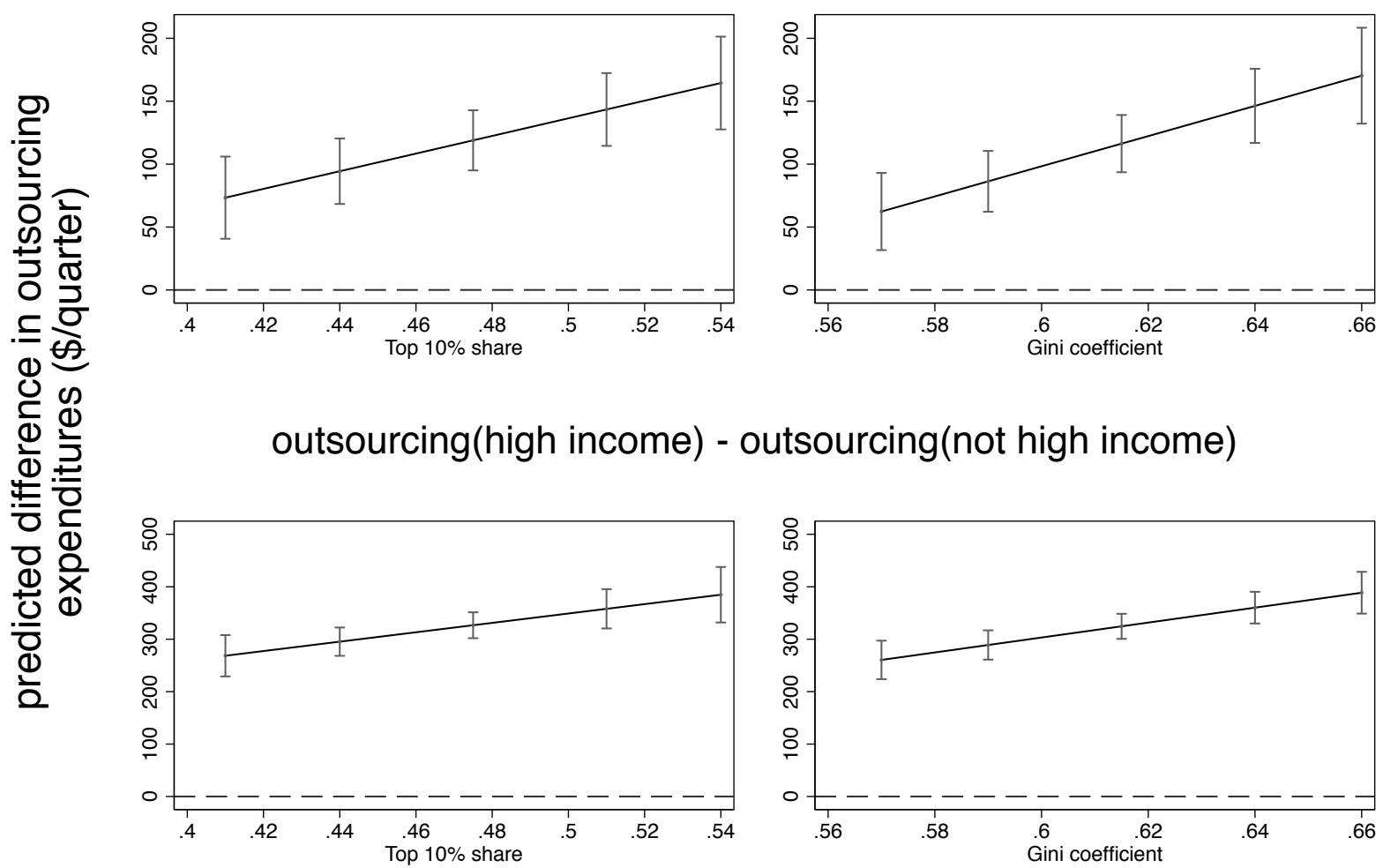

outsourcing(high income) - outsourcing(not high income)

This outsourcing variable includes expenditures on housekeeping services, laundry, and eating out. We note, however, that class differences in the amount of money spent eating out could reflect both differences in the quantity of outsourcing of food preparation and in the cost of the food that is purchased. We re-estimated our models using only expenditures on housekeeping services and found positive interaction terms between SES and inequality, which were statistically significant in 
two of the four model specifications. However, restricting our analysis to only housekeeping services excludes food preparation, which is a substantial portion of women's household labor. Overall, the analysis from both sets of models is consistent with the idea that the class gradient to outsourcing housework is steeper (more positive) in high inequality contexts.

Our analysis of the inequality-related class divides in housework time and in outsourcing expenditures are based on two different data sets. As such, we cannot directly estimate how much of the additional class-difference in housework time stemming from income inequality is attributable to outsourcing stemming from income inequality. We can, however, indirectly estimate this quantity. We show that a 5-point increase in the Gini is associated with a 6 minute/day increase in housework gap, which is 9 hours per quarter. The same Gini increase is associated with a $\$ 60 /$ quarter increase in the outsourcing expenditure gap. If one valued the time at $\$ 8 / \mathrm{hr}$, it would be equivalent to buying 7.5 hours of time, or $83 \%$ of the total hours forgone. This back-of-the-envelope calculation is imprecise in so far as we do not actually know how much time is valued at, as it would vary both by the type of work being outsourced and, as noted above, by the level of inequality. However, this calculation does suggest that, at least in relative size, outsourcing could plausibly explain a significant portion of the increased class gap in housework time.

\section{DISCUSSION}

Income inequality has grown tremendously in the United States over the past 45 years and shows little sign of slowing. We document an intuitive, but empirically overlooked, consequence of this rising inequality in household income: income inequality influences the ability of high- and lowerSES women to hire others to perform domestic work.

We find that the class gradient in women's housework time is steeper in states in which income inequality is higher. Affluent women, as marked by education or household income, do less housework than other women when inequality, as measured by the Gini or the top $10 \%$ share, is more pronounced. Our approach and results advance the limited prior work on this topic by moving (1) from a cross-sectional cross-national design to an analysis of state-level panel data, (2) from the use of country-level aggregates of inequality to state-level aggregates, and (3) from using stylized housework measures to diary estimates. Finally, drawing on expenditures data, our analysis suggests the steeper class gradient in housework time in high inequality contexts could plausibly be the product of increased outsourcing by high-SES women and, perhaps, more constrained outsourcing by lower-SES women. While we are not able to integrate our analysis of housework time and expenditures into a single analysis, our results significantly advance prior work by empirically examining and finding supporting evidence for the outsourcing mechanism.

While much of the prior literature on housework focuses on gender inequalities between men and women, we take a different approach. Our focus is on how area-level income inequality shapes classinequality among women in housework time. Our approach is not then specifically intersectional (McCall, 2001; Cooke, 2011) in that we do not examine how class inequalities shape gender 
inequalities in housework time. However, our results do bear on the intersection of class and gender. If rising income inequality has co-occurred with professional women's increasing work and even overwork, then theories of gendered bargaining and time availability might suggest a re-allocation of housework time along gender lines, with the spouses of high-SES women taking on a more equitable share of housework. The alternative, of course, is that the male spouses of these women would be entirely resistant to taking on more housework time (Ehrenreich and Hochschild, 2011).

In supplemental models, we find that class-divides in women's housework time widened most conspicuously with income inequality among women who work full-time and to a lesser degree for those who work part-time or not at all. This accords with the view that women's employment is a part of the story of income-inequality and housework time. However, we do not find that men married to high-SES women increased their housework time with income inequality as high-SES women decreased theirs (Online Appendix 4). In fact, our results suggest the opposite.

These results raise an interesting question about class divergence in the gender revolution. High-SES women do less housework in contexts of high income inequality. If that reduction came from men doing more housework, then we could think of economic inequalities as potentially reducing some dimension of gender inequality - a tradeoff between economic and gender inequality. But, it does not appear that high-SES men do more. Instead, it is the case that high-SES women appear to reduce their housework time by outsourcing it and that lower-SES women outsource less and do more housework (though it is only the gap that is significant). For high-SES households, economic inequality does not seem to reshape gender inequality.

But, economic inequality may twist gender inequalities differently by class. The inference from our analysis of the CEX is that high-SES women's reductions in housework are accomplished by hiring domestic workers and consuming prepared foods-paid labor often performed by women. On the one hand, such outsourced labor is paid and so rising economic inequality may serve to reallocate unpaid domestic labor by high-SES women to paid domestic labor by low-SES women. On the other hand, these dynamics could reinforce the idea that housework remains women's work, while concentrating that expectation among low-SES women. In this way, economic inequality and gender inequality may rise together. Further, it is possible that by outsourcing domestic work, high-SES women may be able to further specialize in market work, thus potentially increasing income inequality between women and between households. That our results are most pronounced among women working full-time supports this possibility.

Several elements of our analysis are also subject to some important limitations. First, while we find strong results using state-level measures of income inequality, it is possible that smaller geographic units would better capture the labor market dynamics of outsourcing. For a small subsample of respondents, the ATUS also identified the Combined Statistical Area (CSA) that the women resided in. In Online Appendix 4, we present an analysis that substitutes CSA-level inequality (from the American Community Survey) for state-level inequality in the main models. The results are weaker the coefficients have similar magnitude and direction, but have larger standard errors and are not statistically significant. While it may be that the state-level aggregate more closely captures the labor 
market dynamics underlying these relationships, it is also the case that our CSA-level data are fairly limited, both in how many ATUS respondents we can match with CSAs and in how many years we can include (because CSA-level inequality was not calculated from the ACS until 2006). Furthermore, the CEX does not provide any geographic identification smaller than the state level, so we are unable to test our outsourcing mechanisms for smaller areas. These data constraints are a real limit on our analysis and future work that identified data that allowed for testing these smaller-area dynamics would be very valuable.

Second, while we have taken several steps to guard against the risk of omitted variables bias, it remains possible that other unobserved factors could bias the relationships documented here. In particular, unobserved attitudes or cultural scripts correlated with both our economic markers of class and housework time could interact with inequality levels to produce the relationships seen here. Future work could usefully address this potential issue by drawing on the individual-level longitudinal data available in the PSID to estimate individual fixed-effects models of the relationship between changes in socio-economic status, area-level income inequality, and women's housework time.

Third, our estimates do not include expenditures on technology that could be used to reduce women's housework time. While the ownership of labor-saving appliances, specifically a dishwasher and a clothes washer, is widespread, it is steeply graded by household income quintile (Siebens, 2013). It is also certainly possible that these class gaps in the ownership of these appliances and others are wider in more unequal places. If high-SES women use these technologies to reduce their housework time, then they might have less need to hire workers to perform this housework. Thus, we might expect that to the extent that the class-gap in the use of technology to reduce time on domestic labor is wider in more unequal places, that would actually suppress the interaction between class and income inequality in predicting outsourcing expenditures. In this case, our test of the outsourcing mechanism is likely conservative.

Our analysis advances the growing literature on the social and economic effects of high income inequality by returning to the simple idea that relative, rather than absolute, levels of income govern the dynamics of personal labor relations and in particular the engagement of domestic workers. We provide a window into how inequality may structure everyday interpersonal interaction, in this case by perhaps making relations of servitude more common in the domestic sphere. We also advance the nascent literature on the role of economic inequality in class differences in women's housework by adopting a rigorous design to examine how local contexts of inequality shape class divides in housework and outsourcing. More generally, this research contributes to the small but growing body of literature on class differences among women (e.g., McCall, 2007) and how rising economic inequality has served to heighten these divides (e.g., Milkman, 2009). 


\section{About THE Authors}

Daniel Schneider is an Assistant Professor of Sociology at the University of California, Berkeley. His research examines how economic inequality, instability, and job quality affect American families. He has recently published on the economic correlates of marriage (Social Problems, 2014) the effects of the Great Recession on fertility (Demography, 2015; Population and Development Review, 2017), and how precarious scheduling affects family wellbeing (Social Service Review, 2017).

Orestes "Pat" Hastings is an Assistant Professor of Sociology at Colorado State University. He uses surveys, experiments, and administrative data to do research in stratification \& inequality, economic sociology, social psychology, social demography, religion \& spirituality, and quantitative methods. Recent work has appeared in Demography, Social Science Research, and Sociological Science. His

current project examines how income inequality shapes people's perceptions, attitudes, and behaviors. 


\section{REFERENCES}

Bianchi, Suzanne, Melissa Milkie, Liana Sayer, and John Robinson. 2000. "Is Anyone Doing the Housework? Trends in the Gender Division of Household Labor." Social Forces 79(1):191-228.

Brines, Julie. 1993. “The Exchange Value of Housework.” Rationality and Society 5(3):302-340.

Cameron, Colin and Douglas Miller. 2011. "Robust Inference with Clustered Data." In Handbook of Empirical Economics and Finance, Eds. A. Ullah and D. E. Giles. pp. 1-28, CRC Press.

Cooke, Lynn Prince and Lianna Sayer. 2012. "The Context of Relative Equality: Comparing Educational Gradients in the Gendered Division of Labor in Three Liberal Markets." LIS Working Paper Series No. 578.

Cooke, Lynn Prince. 2011. Gender-Class Equality in Political Economies. Routledge.

Coser, Louis. 1973. "Servants: The Obsolescence of an Occupational Role.” Social Forces 52(1):31-40.

Craig, Lyn, Francisco Pereales, Sergi Vidal, Janeen Baxter. 2016. "Domestic Outsourcing, Housework Time, and Subjective Time Pressure: New Insights From Longitudinal Data." Journal of Marriage and Family 78(5):1224-1236.

Deaton, Angus. 2003. "Health, Inequality, and Economic Development." Journal of Economic Literature 41(1):113-158.

De Ruijter, Esther, Judith Treas, and Philip Cohen. 2005. "Outsourcing the Gender Factory: Living Arrangements and Service Expenditures on Female and Male Tasks.” Social Forces 84: 306-22.

Edin, Kathryn and Laura Lein. 1997. Making Ends Meet. New York: Russell Sage Foundaton.

England, Paula and Anjula Srivastava. 2013. "Educational Differences in US Parents? Time Spent in Child Care: The Role of Culture and Cross-Spouse Influence.” Social Science Research 42:971-988.

Ehrenreich, Barbara and Arlie Hochschild. 2004. Global Woman: Nannies, Maids, and Sex Workers in the New Economy Holt.

Frank, Mark. 2014. “A New State-Level Panel of Annual Inequality Measures over the Period 1916 2005" Journal of Business Strategies 31(1):241-263.

Frank, Mark, Estelle Sommeiller, Mark Price, and Emmanuel Saez. 2015. "Frank-Sommeiller-Price Series for Top Income Shares by US States since 1917." The World Top Incomes Database Methodological Notes.

Gupta, Sanjiv, Marie Evertsson, Daniela Grunow, Magnus Nermo, and Liana Sayer. 2010. "Economic Inequality and Housework." In Dividing the Domestic: Men, Women, \& Household Work in Cross-National Perspective Eds. Judith Treas and Sonja Drobnic. pp. 105-124. Stanford, CA: Stanford University Press.

Gupta, Sanjiv. 2006. "Her Money, Her Time: Women's Earnings and Their Housework Hours.” Social Science Research 35:975-999. 
Heimdal, Kristen and Sharon Houseknecht. 2003. "Cohabiting and Married Couples' Income Organization: Approaches in Sweden and the United States." Journal of Marriage and Family 65(3):525-538.

Heisig, Jan Paul. 2011. "Who Does More Housework: Rich or Poor?: A Comparison of 33 Countries.” American Sociological Review 76(1):74-99.

Hondagneu-Sotelo, Pierrette. 2007. Domestica: Immigrant Workers Cleaning and Caring in the Shadows of Affluence. Berkeley: University of California Press.

Jencks, Christopher, Marshall Smith, Henry Acland, Mary Jo Bane, David Cohen, Herbert Gintis, Barbara Heyns, and Stephen Michelson. 1972. Inequality: A Reassessment of the Effect of Family and Schooling in America. New York: Basic Books.

Kan, Man Yee. 2008. "Measuring Housework Participation: The Gap between "Stylised" Questionnaire Estimates and Diary-based Estimates." Social Indicators Research 86:381-400.

Kornrich, Sabino. 2012. "Hiring Help for the Home Household Services in the Twentieth Century." Journal of Family History 37(2):197-212.

Killewald, Alexandra. 2011. "Opting Out and Buying Out: Wives' Earnings and Housework Time." Journal of Marriage and Family 73:459-471.

McCall, Leslie. 2007. "Increasing Class Disparities among Women and the Politics of Gender Equity.” In The Sex of Class, ed. D.S. Cobble, 15-34. Ithaca, NY: Cornell University Press.

McCall, Leslie. 2001. Complex Inequality: Gender, Class, and Race in the New Economy. Routledge.

Milkman, Ruth. 2009. "Class Disparities, Market Fundamentalism and Work-Family Policy: Lessons from California.” pp. 339-364. In Gender Equality: Transforming Family Divisions of Labor, eds. Erik Olin Wright, Janet Gornick, and Marcia Meyers. New York: Verso.

Milkman, Ruth, Ellen Reese, and Benita Roth. 1998. "The Macro-Sociology of Paid Domestic Labor." Work and Occupations 25(4):483-510.

Parrenas, Rhacel Salazer. 2015. Servants of Globalization: Women, Migration, and Domestic Work. Stanford: Stanford University Press.

Piketty, Thomas and Emmanuel Saez. 2014. "Inequality in the Long Run." Science 344(6186):838843.

Romero, Mary. 1992. Maid in the U.S.A. Routledge.

Sassen, Saskia. 1991. The Global City. Princeton: Princeton University Press.

Schneider, Daniel. 2011. "Market Earnings and Household Work: New Tests of Gender Performance Theory." Journal of Marriage and Family 73: 845-860.

Shelton, Beth Ann and Daphne John. 1996. "The Division of Household Labor." Annual Review of Sociology 22:299-322. 
Siebens, Julie. 2013. "Extended Measures of Well-Being: Living Conditions in the United States: 2011.” U.S. Department of Commerce Economics and Statistics Administration, U.S. Census Bureau.

South, Scott and Glenna Spitze. 1994. "Housework in Marital and Nonmarital Households." American Sociological Review 59(3):327-347.

Spitze, Glenna. 1999. "Getting Help with Housework: Household Resources and Social Networks." Journal of Family Issues 20(6):724-745.

Stigler, Geroge. 1946. Domestic Servants in the United States, 1900-1940 (\#24). New York: National Bureau of Economic Research.

Treas, Judith and Esther deRuitjer. 2008. "Earnings and Expenditures on Household Services in Married and Cohabiting Unions." Journal of Marriage and Family 70:796-805.

Treas, Judith and Jonathan Liu. 2013. "Studying Housework Across Nations." Journal of Family Theory \& Review 5:135-149.

Veblen, Thorstein. [1899] 1963. A Theory of the Leisure Class: An Economic Study of Institutions. New York: New American Library.

Wilkinson, Richard and Kate Pickett. 2009. "Income Inequality and Social Dysfunction.” Annual Review of Sociology 35:493-511. 


\section{ENDNOTES}

1. We also tested the proportion of immigrants among the entire working age population, proportion of immigrants with no more than a high school diploma and not in school among all working age, and the proportion of female immigrants among all working age females. For each of these we found comparable results.

2. For $14 \%$ of records, the state of residence was suppressed to meet the Census Disclosure Review Board's criterion that the smallest geographically identifiable areas have a population of at least 100,000 . Furthermore, $4 \%$ of state codes were replaced with codes of states other than the state where the household resides. We created a dichotomous indicator of whether a state included recodes from another state. In our analysis, we include states with some recodes, but find similar results when excluding them.

3. There are two levels of clustering, because households are observed up to four times. We cluster at the highest level (states). The clustered variance estimator accommodates an arbitrary variancecovariance matrix within each cluster, so it is robust to the presence of lower levels of clustering-in this case the multiple household observations within each state (Cameron and Miller 2011).

4. We also estimated identical models that dis-aggregated time into housekeeping and meal-related work. The coefficients in each model are of course smaller (since fewer activities or expenditure categories are included as compared to the preferred models) and not all the differences are statistically significant. But, in short, the widening of class gaps in both time and expenditures with income inequality appears for both categories of outcomes. There is then good justification for combining these two broad categories of domestic labor and spending. 